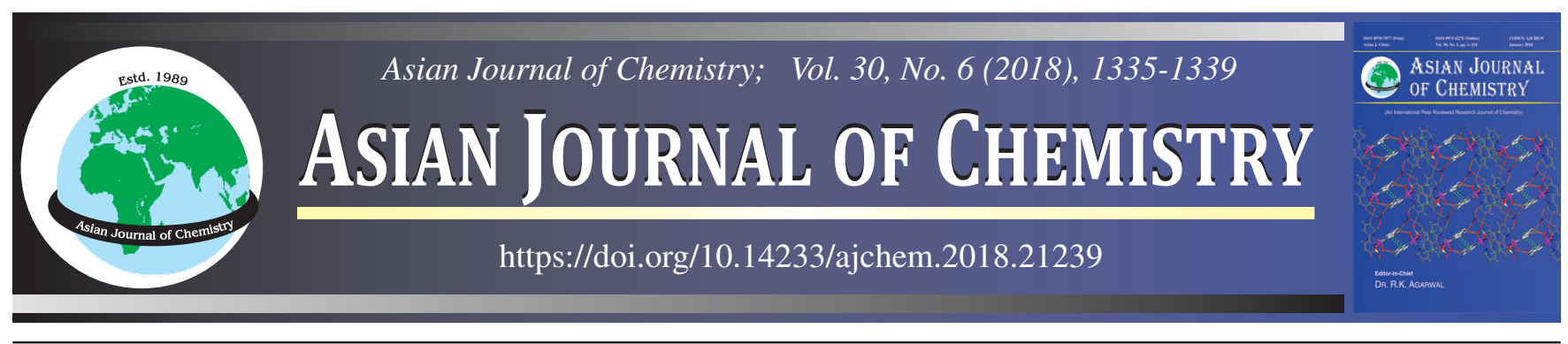

\title{
A Computational Study of Anticancer Activity of Curcumin Derivatives Using in silico Drug Designing and Molecular Docking Tools
}

\section{S. Shefrin, Asha Asokan Manakadan* and T.S. Saranya}

Department of Pharmaceutical Chemistry \& Analysis, Amrita School of Pharmacy, Amrita Vishwa Vidyapeetham, AIMS Health Science Campus, AIMS Ponekkara P.O., Kochi-682 041, India

*Corresponding author: E-mail: asha19484@aims.amrita.edu; ashaabhijath@gmail.com

Received: 18 January 2018;

Accepted: 20 February 2018;

Published online: 30 April 2018;

AJC-18890

Cancer is an abnormal growth of cells beyond a defined area. Curcumin, the principal curcuminoid of turmeric (Curcuma longa), have wide therapeutic uses like anti-inflammatory, antitumor activities, etc. The present study aims to propose anticancer activity of 11 curcumin derivatives which include curcubitacin $\mathrm{E}$, demethoxycurcumin, bisdemethoxycurcumin, $\alpha$-elemene, (-) $\beta$-elemene, $(-) \delta$-elemene, $(-) \gamma$ elemene, germacrone, curdione, furanodiene, calebin A and aromatic turmerone, against a standard drug, megestrol acetate used for the treatment of endometrial cancer, using computer aided drug designing (CAAD). The computational studies include calculation of bioactivity scores, molecular properties, analysis of primary and secondary structure of protein, toxicity prediction using various online tools including admetSAR, Pass Server, PepDraw, RaptorX, Molinspiration, ChemSketch and SwissPDB. The docking score of 11 ligands and Megestrol acetate was found using ArgusLab 4.0.1. It was interpreted that these molecules could be a great lead for further development of anticancer drug against the disease.

Keywords: Endometrial carcinoma, Curcumin, Tumor protein p53, Megestrol acetate, Molecular docking analysis.

ᄂ _ _ - - _ - - - - _ - - - - - - - - - - - - - - - - - - - -

\section{INTRODUCTION}

Endometrial cancer is a frequently diagnosed gynaecological cancer, mostly found in women of age group less than 55 years. According to the 2016 surveillance of the National Cancer Institute, estimated new cases in US was found to be 60,050 and estimated death was found to be 10,470 . Whereas in India, the rate of mortality is comparatively lower which is almost 4773 . The percentage of survival was found to be $81.7 \%$ from 2006-2012. The western culture is portrayed by high calorie diet, food rich in fat, along with low physical activity resulted in overall energy imbalance. Malignancies typically occurring in well-to-do societies are carcinomas of breast, colon, uterus (endometrial carcinoma), gallbladder, kidney [1]. The type 2 endometrial cancer, common in $90 \%$ population, occurs due to mutations in tumor suppressor protein p53 [2]. It is present in the $17^{\text {th }}$ chromosome of short arm and functions as "Preserver of Genome" by conserving the stability and preventing gene mutations. Normally TP53 gene encoded protein merges with the DNA and regulate gene execution to prevent modification of the genome. Mdm2 (Mouse double minute 2 homolog) acts as a negative regulator of p53. Thus on any type of DNA damage, (like cell cycle abnormalities, hypoxia) complex formation of proteins occurs and thus inhibits transcriptional activity of p53. Once it is activated it induces cell cycle arrest and therefore repair or apoptosis of damaged cell occurs. In case of eccentric functioning, (90\% in serous carcinoma) mutations in DNA causes accumulation of nuclear p53 and restraining of cell cycle by inhibiting cyclin D1 phosphorylation at $\mathrm{N}$-terminal domain thus increasing apoptosis. Thus mutated $\mathrm{p} 53$ produces nonfunctional protein that accumulates in the cell acting as a double negative inhibitor thus increasing rapidly number of abberent cells [3,4]. The aim of the study was to prove that anticancer activity of curcumin derivatives can be utilized to produce safer drugs for the treatment of malignant tumor as herbal approaches can be utilized to minimize side effects.

\section{EXPERIMENTAL}

The structure of target protein were obtained from RCBS protein data bank and saved as PDB file [5]. The file was opened using ArgusLab 4.0.1 and all the water molecules were removed and finally saved it.

The protein was conducted with online tools like PepDraw, RaptorX to obtain the primary and secondary structure of the protein [6,7]. The selected ligands of curcumin derivatives curcubitacin E, demethoxycurcumin, bisdemethoxycurcumin, $\alpha$-elemene, (-) $\beta$-elemene, (-) $\delta$-elemene, (-) $\gamma$-elemene, germa- 


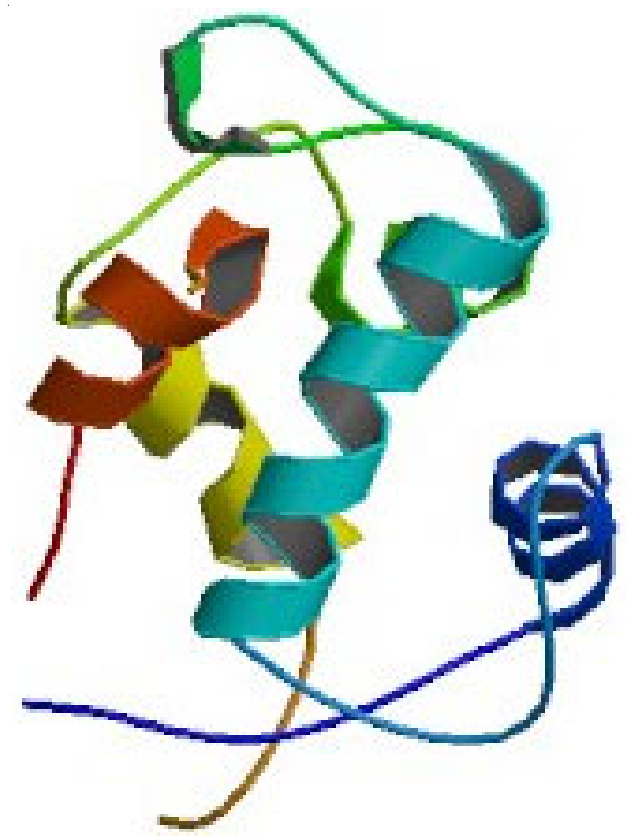

Fig. 1. p53 protein with PDB ID: 2MWY

crone, curdione, furanodiene, calebin A and aromatic turmerone, conjointly with the standard drug, megestrol acetate was drawn in ChemSketch and SMILE notation was obtained [8]. Energy extension was decided by CORINA [9]. Molecular properties and bioactivity score was figured using the online tool Molinspiration [10]. The drug trend was tallied using various parameters like total polar surface area (TPSA), number of atoms (nAtoms), molecular weight (MW), number of hydrogen bond acceptors, number of hydrogen bond donors, number of violations (nViolations) and number of rotatable bonds. The ADMET (absorption, distribution, metabolism, excretion and toxicity) properties of drug candidates were computed using the online tool admetSAR, using various parameters like blood-brainbarrier, intestinal absorption, carcinogenicity, biodegradation, etc. [11]. The various activities of ligands like pharmacological actions, antineoplastic activities was calculated using online tool PASS Server [12]. The ligands were finally headed up for docking using ArgusLab 4.0.1 software which is achieved by the Lamarckian genetic algorithm, to get the docking scores (Ligand binding pose energy) and thus compared with the standard drug, megestrol acetate $[13,14]$.
Megestrol acetate is a synthetically derived naturally occurring steroidal hormone, progesterone. It acts as a competitive agonist of progesterone receptor and as a result of its activation, antigonadotropic effects are activated. Thus decreasing secretion of Gonadotropins, (responsible of signaling progesterone, estrogen release) thus resulting in decreased levels of sex hormones. Thus the drug reports amongst the most useful effects against estrogen sensitive cancers like breast cancer and endometriosis.

\section{RESULTS AND DISCUSSION}

Molecular activity prediction: Eleven curcuminoids from curcumin having anticancer activity and megestrol acetate was selected as fragments for the work. The selected ligands were dealt with online tool Molinspiration and calculated their bioactivity score and molecular properties [15]. The presumption with the ligands was calculated using various parameters like MiLogP, TPSA, nAtoms, MW, nON, nOHNH, nViolations, nRotb and volume as in Table-1. TPSA is the Total polar surface area, nAtoms- number of atoms, MW- molecular weight, nONnumber of hydrogen bond acceptors, nOHNH- number of hydrogen bond donors and nrotb - number of rotatable bonds.

The work was based on the key concept of "LIPINSKY RULE OF FIVE", which schemed certain standards for interpretation; The $\log \mathrm{P}$ value must not be greater than 5; curcubitacin E, demethoxycurcumin, bisdemethoxycurcumin, curdione, furanodiene, calebin A, curdione, ar-turmerone have satisfactory results, showing moderate permeability to Blood-BrainBarrier and good penetration to the plasma membranes of the cell. A value greater than 2 always shows good BBB passage [16]. Molecular weight must not be greater than 500 Daltons; demethoxycurcumin, bisdemethoxycurcumin, $\alpha$-elemene, (-) $\beta$-elemene, (-) $\delta$-elemene, (-) $\gamma$-elemene, curdione, calebin A, ar-turmerone obeys the rule. Total polar surface area value should be less than $160 \AA$; which obeyed by all the ligands. nViolations must be equal to 1 or less than 0 ; which is obeyed by all ligands. Number of rotatable bonds must be less than 10; which is obeyed by all ligands. Number of $\mathrm{H}$-bond acceptors must be less than or equal to 10; is satisfied by all ligands. Number of H-bond donors must be less than or equal to 5; satisfied by all ligands [17]. The molecular properties of the standard drug, megestrol acetate was also calculated using the

TABLE-1

COMPUTATION OF DRUG LIKELINESS OF CURCUMINOIDS AND STANDARD DRUG USING MOLINSPIRATION

\begin{tabular}{|c|c|c|c|c|c|c|c|c|c|}
\hline Name of Ligand & miLogP & TPSA & nAtoms & MW & nON & nOHNH & nViolations & nRotb & Volume \\
\hline Curcubitacin E & 3.80 & 138.2 & 43 & 598.78 & 8 & 3 & 1 & 6 & 575.01 \\
\hline Demethoxycurcumin & 3.67 & 83.83 & 28 & 380.44 & 5 & 2 & 0 & 8 & 356.26 \\
\hline Bisdemethoxycurcumin & 2.67 & 74.6 & 23 & 308.33 & 4 & 2 & 0 & 6 & 281.09 \\
\hline$\alpha$-Elemene & 5.44 & 0 & 16 & 218.38 & 0 & 0 & 1 & 3 & 250.90 \\
\hline$(-) \beta$-Elemene & 5.37 & 0 & 15 & 204.36 & 0 & 0 & 1 & 3 & 235.23 \\
\hline$(-) \delta$-Elemene & 5.62 & 0 & 16 & 218.38 & 0 & 0 & 1 & 4 & 251.48 \\
\hline$(-) \gamma$-Elemene & 5.42 & 0 & 15 & 204.36 & 0 & 0 & 1 & 2 & 234.65 \\
\hline Germacrone & 6.62 & 17.07 & 20 & 876.46 & 1 & 0 & 1 & 7 & 313.56 \\
\hline Curdione & 4.20 & 34.14 & 18 & 250.38 & 2 & 0 & 0 & 1 & 267.67 \\
\hline Furanodiene & 4.63 & 13.14 & 16 & 216.32 & 1 & 0 & 0 & 0 & 226.49 \\
\hline Calebin A & 2.73 & 102.3 & 28 & 384.38 & 7 & 2 & 0 & 9 & 341.17 \\
\hline ar-turmerone & 4.48 & 17.07 & 16 & 216.32 & 1 & 0 & 0 & 4 & 230.32 \\
\hline Megestrol acetate & 6.22 & 43.38 & 30 & 410.60 & 3 & 0 & 1 & 3 & 414.87 \\
\hline
\end{tabular}


same tool and compared with the values of ligands calculated. The bioactivity score of the ligands was also computed with the help of the same online tool, as illustrated in Table-2. The bioactivity scores were proposed using parameters like GPCR ligand, ion channel modulator, kinase inhibitor, nuclear receptor ligand, protease inhibitor, enzyme inhibitor. The bioactivity score if more than 0.00 is having most considerable biological activity, whereas values -0.50 to 0.00 are moderately active and the ones less than -0.50 are inactive [18]. The score for GPCR ligands was found to be least for ar-turmerone (0.68) and highest for Curcubitacin E (0.12). The ion channel modulator allowed the movement of particles with charge across the cell membrane and act as one of the important therapeutic targets [19]. The score for the parameter of some compounds like curcubitacin E, bisdemethoxycurcumin, germacrone, furanodiene, ar-turmerone was found between 0.00 to -0.50 , suggesting their considerable interaction with this target. The kinase inhibititors for the development of selective blockers that modulate diseased signaling pathways are found to have suitable approach for drug development [20]. The results from kinase inhibition shows that demethoxycurcumin, bisdemethoxycurcumin, (-) $\gamma$-elemene, Calebin A, gives score more than -0.50 , whereas other molecules where inactive towards this target. The score for nuclear receptor ligand, protease inhibition, enzyme inhibition were in ranges of 0.51-0.84, 0.080.33, 0.43-0.66, inputs highly bioactive molecules [21].

ADME and toxicity prediction: The ADMET (absorption, distribution, metabolism, excretion and toxicity) properties of drug candidates was calculated by an online tool, AdmetSAR. Such properties of drug play an important role in drug discovery and environmental hazard management. The ligands taken for the study and the standard drug, megestrol acetate was used as inputs for the calculation and the outcomes are tabulated in Tables 3-6. The human intestinal absorption (HIA) value is greater means the compound could be better absorbed from the intestinal tract upon oral administration [22].

The cytochrome p450 super family play useful role in metabolism and clearance of drugs in liver. Important isoforms of the enzyme include CYP1A2, CYP2A6, CYP2C9 etc. Thus by blocking these isoforms, it leads to drug-drug interaction in which the co-administered drug fails to metabolize and builds up to produce toxic doses.

Activity prediction: The online tool Pass Server is used to predict the biological potency of a drug-like molecule with its pharmacological actions, toxic and adverse effects, influence on enzymes, transporters, genetic expression etc. The prediction of 11 curcumin derivatives and the standard drug, megestrol acetate is analyzed and computed in Table-7.

TABLE-2

COMPUTATION OF BIOACTIVITY SCORE OF THE LIGANDS

\begin{tabular}{|c|c|c|c|c|c|c|}
\hline Name of Ligand & GPCR ligand & $\begin{array}{c}\text { Ion channel } \\
\text { modulator }\end{array}$ & $\begin{array}{l}\text { Kinase } \\
\text { inhibitor }\end{array}$ & $\begin{array}{l}\text { Nuclear } \\
\text { receptor ligand }\end{array}$ & $\begin{array}{l}\text { Protease } \\
\text { inhibitor }\end{array}$ & $\begin{array}{l}\text { Enzyme } \\
\text { inhibitor }\end{array}$ \\
\hline Curcubitacin $\mathrm{E}$ & 0.12 & -0.44 & -0.58 & 0.23 & 0.01 & 0.12 \\
\hline Demethoxycurcumin & -0.04 & -0.2 & -0.26 & 0.18 & -0.14 & 0.1 \\
\hline Bisdemethoxycurcumin & 0 & -0.14 & -0.26 & 0.25 & -0.08 & 0.15 \\
\hline$\alpha$-Elemene & -0.51 & 0.06 & -0.76 & 0.7 & -0.48 & 0.42 \\
\hline (-) $\beta$-Elemene & -0.36 & 0.18 & -1.2 & 0.43 & -0.38 & 0.3 \\
\hline$(-) \delta$-Elemene & -0.2 & 0.16 & -0.78 & 0.73 & -0.36 & 0.51 \\
\hline$(-) \gamma$-Elemene & -0.46 & 0.02 & -0.01 & 0.51 & -0.71 & 0.24 \\
\hline Germacrone & -0.3 & -0.05 & -0.58 & 0.16 & -0.44 & 0.14 \\
\hline Curdione & -0.38 & 0.04 & -0.93 & -0.01 & -0.27 & 0.24 \\
\hline Furanodiene & -0.32 & -0.32 & -0.84 & -0.05 & -0.91 & 0.1 \\
\hline Calebin A & -0.21 & -0.4 & -0.36 & -0.02 & -0.16 & -0.08 \\
\hline ar-turmerone & -0.68 & -0.46 & -1.36 & -0.14 & -0.8 & -0.25 \\
\hline Megestrol acetate & 0.01 & 0.08 & -0.55 & 0.9 & 0.04 & 0.37 \\
\hline
\end{tabular}

TABLE-3

ABSORPTION, DISTRIBUTION, METABOLISM, EXCRETION AND TOXICITY PREDICTIONS USING AdmetSar

\begin{tabular}{|c|c|c|c|c|c|c|}
\hline Name of Ligand & $\begin{array}{l}\text { Blood brain } \\
\text { barrier }\end{array}$ & $\begin{array}{c}\text { Human intestinal } \\
\text { absorption }\end{array}$ & $\begin{array}{c}\text { Caco2 } \\
\text { Permea-Bility }\end{array}$ & $\begin{array}{l}\text { p-Glyco protein } \\
\text { substrate }\end{array}$ & $\begin{array}{l}\text { p-Glyco protein } \\
\text { inhibitor }\end{array}$ & $\begin{array}{c}\text { Renal } \\
\text { organic cation } \\
\text { transporter }\end{array}$ \\
\hline Curcubitacin $\mathrm{E}$ & 0.7611 & 0.9426 & 0.5911 & 0.7372 & 0.5243 & 0.8858 \\
\hline Demethoxycurcumin & 0.6222 & 0.9642 & 0.6494 & 0.5453 & 0.523 & 0.8553 \\
\hline Bisdemethoxycurcumin & 0.7886 & 0.9809 & 0.6953 & 0.6076 & 0.8771 & 0.8614 \\
\hline$\alpha$-Elemene & 0.9187 & 0.9843 & 0.7444 & 0.6488 & 0.6396 & 0.7824 \\
\hline$(-) \beta$-Elemene & 0.9285 & 0.9842 & 0.7521 & 0.6349 & 0.7043 & 0.7311 \\
\hline$(-) \delta$-Elemene & 0.9187 & 0.9843 & 0.7444 & 0.6488 & 0.6396 & 0.7824 \\
\hline$(-) \gamma$-Elemene & 0.9047 & 0.9874 & 0.7048 & 0.6066 & 0.6499 & 0.7643 \\
\hline Germacrone & 0.9300 & 1.0000 & 0.7830 & 0.5124 & 0.5144 & 0.8257 \\
\hline Curdione & 0.8275 & 1.0000 & 0.6804 & 0.5237 & 0.6046 & 0.9093 \\
\hline Furanodiene & 0.9810 & 1.0000 & 0.6764 & 0.5462 & 0.5344 & 0.7953 \\
\hline Calebin A & 0.6259 & 0.8611 & 0.6404 & 0.5125 & 0.6060 & 0.8391 \\
\hline ar-turmerone & 0.9505 & 1.0000 & 0.8342 & 0.6188 & 0.5000 & 0.8574 \\
\hline Megestrol acetate & 0.9542 & 0.9920 & 0.5792 & 0.6070 & 0.8503 & 0.7508 \\
\hline
\end{tabular}




\begin{tabular}{|c|c|c|c|c|c|}
\hline \multicolumn{6}{|c|}{$\begin{array}{c}\text { TABLE-4 } \\
\text { AdmetSar PREDICTION }\end{array}$} \\
\hline Name of Ligand & AMES test & Carcinogens & $\begin{array}{l}\text { Rat-Acute toxicity } \\
\text { (LD50.mol/kg) }\end{array}$ & Biodegradation & $\begin{array}{l}\text { Carcinogenicity } \\
\text { (three-class) }\end{array}$ \\
\hline Curcubitacin E & Non AMES toxic & Non-Carcinogens & 3.5441 & 0.9935 & 0.5213 \\
\hline Demethoxycurcumin & Non AMES toxic & Non-Carcinogens & 2.2792 & 0.9000 & 0.6580 \\
\hline Bisdemethoxycurcumin & Non AMES toxic & Non-Carcinogens & 2.2754 & 0.8254 & 0.5765 \\
\hline$\alpha$-Elemene & Non AMES toxic & Non-Carcinogens & 1.4826 & 0.5606 & 0.4648 \\
\hline$(-) \beta$-Elemene & Non AMES toxic & Non-Carcinogens & 1.2815 & 0.5496 & 0.4679 \\
\hline$(-) \delta$-Elemene & Non AMES toxic & Non-Carcinogens & 1.4826 & 0.5606 & 0.4648 \\
\hline$(-) \gamma$-Elemene & Non AMES toxic & Non-Carcinogens & 1.3653 & 0.6802 & 0.4728 \\
\hline Germacrone & Non AMES toxic & Non-Carcinogens & 2.0596 & 0.7447 & 0.5634 \\
\hline Curdione & Non AMES toxic & Non-Carcinogens & 2.0083 & 0.9048 & 0.7275 \\
\hline Furanodiene & Non AMES toxic & Non-Carcinogens & 1.7987 & 0.6138 & 0.4425 \\
\hline Calebin A & Non AMES toxic & Non-Carcinogens & 2.2027 & 0.7017 & 0.7586 \\
\hline ar-turmerone & Non AMES toxic & Carcinogens & 1.5976 & 0.7554 & 0.5252 \\
\hline Megestrol acetate & Non AMES toxic & Non-Carcinogens & 1.8669 & 0.9408 & 0.5917 \\
\hline
\end{tabular}

TABLE-5

AdmetSar PREDICTION

\begin{tabular}{lcccc}
\hline \multicolumn{1}{c}{ Name of Ligand } & CYP450 2C9 substrate & CYP450 2D6 substrate & CYP450 3A4 substrate & CYP450 1A2inhibitor \\
\hline Curcubitacin E & 0.8459 & 0.9020 & 0.7448 & 0.8707 \\
Demethoxycurcumin & 0.7286 & 0.8878 & 0.5927 & 0.8959 \\
Bisdemethoxycurcumin & 0.7770 & 0.9173 & 0.6887 & 0.5302 \\
$\alpha$-Elemene & 0.8529 & 0.7988 & 0.5087 & 0.7657 \\
$(-)$-Elemene & 0.8749 & 0.8276 & 0.5958 & 0.7548 \\
$(-)$-Elemene & 0.8529 & 0.7988 & 0.5087 & 0.7657 \\
$(-)$-Elemene & 0.8662 & 0.8115 & 0.5101 & 0.7516 \\
Germacrone & 0.8577 & 0.8142 & 0.6390 & 0.5955 \\
Curdione & 0.8329 & 0.8767 & 0.5426 & 0.8591 \\
Furanodiene & 0.8390 & 0.8037 & 0.5376 & 0.7744 \\
Calebin A & 0.7684 & 0.8998 & 0.5000 & 0.6595 \\
ar-turmerone & 0.8416 & 0.8563 & 0.5000 & 0.5650 \\
Megestrol acetate & 0.8607 & 0.9085 & 0.7469 & 0.9066 \\
\hline
\end{tabular}

TABLE-6

AdmetSar PREDICTION

\begin{tabular}{|c|c|c|c|c|c|}
\hline Name of Ligand & $\begin{array}{c}\text { CYP450 2C9 } \\
\text { inhibitor }\end{array}$ & $\begin{array}{l}\text { CYP450 2D6 } \\
\text { inhibitor }\end{array}$ & $\begin{array}{c}\text { CYP450 2C19 } \\
\text { inhibitor }\end{array}$ & $\begin{array}{c}\text { CYP450 3A4 } \\
\text { inhibitor }\end{array}$ & $\begin{array}{c}\text { CYP inhibitory } \\
\text { promiscuity }\end{array}$ \\
\hline Curcubitacin E & 0.8712 & 0.9358 & 0.8867 & 0.7699 & 0.8587 \\
\hline Demethoxycurcumin & 0.7864 & 0.5346 & 0.8365 & 0.6654 & 0.5691 \\
\hline Bisdemethoxycurcumin & 0.5345 & 0.8345 & 0.6365 & 0.6661 & 0.5369 \\
\hline$\alpha$-Elemene & 0.9040 & 0.9339 & 0.8322 & 0.9523 & 0.6449 \\
\hline$(-) \beta$-Elemene & 0.9345 & 0.9354 & 0.8600 & 0.9376 & 0.6834 \\
\hline$(-) \delta$-Elemene & 0.9040 & 0.9339 & 0.8322 & 0.9523 & 0.6449 \\
\hline$(-) \gamma$-Elemene & 0.8822 & 0.9440 & 0.8247 & 0.9412 & 0.6566 \\
\hline Germacrone & 0.8742 & 0.9497 & 0.8145 & 0.9215 & 0.8579 \\
\hline Curdione & 0.9261 & 0.9246 & 0.9320 & 0.8650 & 0.9840 \\
\hline Furanodiene & 0.7483 & 0.8884 & 0.5812 & 0.8795 & 0.5526 \\
\hline Calebin A & 0.8544 & 0.7221 & 0.7389 & 0.6472 & 0.5590 \\
\hline ar-turmerone & 0.8061 & 0.9002 & 0.7469 & 0.8097 & 0.5914 \\
\hline Megestrol acetate & 0.8663 & 0.9378 & 0.8702 & 0.8715 & 0.8981 \\
\hline
\end{tabular}

Molecular docking analysis: The docking of 11 curcuminoids with the standard drug, megestrol acetate was done using ArgusLab 4.0.1 to obtain docking scores from their interactional energies. The protein with PDB ID-5C5A was docked with the ligands and the standard drug, megestrol acetate. The results showed that the protein has considerable interaction with the ligands as tabulated in Table- 8 .

The interpretation of result clearly confirms that ligands $\alpha$-elemene, (-) $\gamma$-elemene, ar-turmerone, (-) $\beta$-elemene, deme- thoxycurcumin, ar-turmerone, bisdemethoxycurcumin showed considerably good docking results, except curcubitacin E. All the ligands were docked with the protein selected and compared to the standard drug, megestrol acetate by its docking score [23].

\section{Conclusion}

Docking studies enhanced ligand precision and even though drug produces unsatisfactory desired effects by binding 
TABLE-7

TABULATION OF RESULTS OF PASS SERVER

\begin{tabular}{|c|c|c|c|c|c|c|c|c|}
\hline \multirow[t]{2}{*}{ Name of Ligands } & \multicolumn{2}{|c|}{ Antineoplastic } & \multicolumn{2}{|c|}{$\begin{array}{l}\text { Antineoplastic } \\
\text { (breast cancer) }\end{array}$} & \multicolumn{2}{|c|}{$\begin{array}{c}\text { Antineoplastic } \\
\text { (endocrine cancer) }\end{array}$} & \multicolumn{2}{|c|}{ Cytotoxic } \\
\hline & $\mathrm{Pa}$ & $\mathrm{Pi}$ & $\mathrm{Pa}$ & $\mathrm{Pi}$ & $\mathrm{Pa}$ & $\mathrm{Pi}$ & $\mathrm{Pa}$ & $\mathrm{Pi}$ \\
\hline Curcubitacin E & 0.939 & 0.004 & 0.247 & 0.073 & - & - & 0.620 & 0.011 \\
\hline Demethoxycurcumin & 0.689 & 0.028 & 0.545 & 0.015 & 0.141 & 0.043 & 0.451 & 0.033 \\
\hline Bisdemethoxycurcumin & 0.644 & 0.036 & 0.478 & 0.021 & - & - & 0.424 & 0.037 \\
\hline$\alpha$-Elemene & - & - & - & - & - & - & 0.218 & 0.085 \\
\hline (-) $\beta$-Elemene & 0.530 & 0.063 & 0.159 & 0.129 & 0.493 & 0.003 & 0.163 & 0.118 \\
\hline$(-) \delta$-Elemene & 0.405 & 0.103 & - & - & 0.467 & 0.004 & 0.199 & 0.096 \\
\hline$(-) \gamma$-Elemene & - & - & - & - & 0.465 & 0.004 & - & - \\
\hline Germacrone & 0.299 & 0.153 & 0.219 & 0.085 & 0.205 & 0.043 & 0.451 & 0.033 \\
\hline Curdione & 0.598 & 0.045 & 0.170 & 0.116 & 0.157 & 0.119 & 0.494 & 0.026 \\
\hline Furanodiene & 0.723 & 0.022 & - & - & - & - & 0.388 & 0.043 \\
\hline Calebin A & 0.721 & 0.023 & 0.429 & 0.027 & - & - & 0.344 & 0.050 \\
\hline ar-turmerone & 0.449 & 0.087 & 0.317 & 0.050 & - & - & 0.234 & 0.078 \\
\hline Megestrol acetate & 0.695 & 0.027 & 0.270 & 0.064 & - & - & 0.302 & 0.057 \\
\hline
\end{tabular}

- Pa: Probability to be active, Pi: Probability to be inactive

- $\mathrm{Pa}$ and $\mathrm{Pi}$ values vary from 0 to 1 and $\mathrm{Pa}+\mathrm{Pi}$ is less than 1 , since these probabili-ties are calculated independently

- The results suggest that highest Pa values were obtained than Pi for compounds exhibiting antineoplastic property and thus showing high grade anticancerous potential [Ref. 24]

\section{TABLE-8}

\begin{tabular}{lc}
\hline \multicolumn{1}{c}{ Name of Ligands } & Docking energy (kcal/mol) \\
\hline Curcubitacin E & No acceptable ligand poses \\
Demethoxycurcumin & -8.53689 \\
Bisdemethoxycurcumin & -8.45303 \\
$\alpha$-Elemene & -9.08323 \\
$(-)$-Elemene & -8.61780 \\
$(-)$-Elemene & -8.58700 \\
$(-) \gamma$-Elemene & -8.83566 \\
Germacrone & -7.96266 \\
Curdione & -8.35975 \\
Furanodiene & -8.27841 \\
Calebin A & -7.16679 \\
ar-turmerone & -8.67823 \\
Megestrol acetate & -6.34774 \\
\hline
\end{tabular}

with another macromolecules, it is possible to dwindle affinity to the opposing site so as to achieve prolonged curative effect [25]. The computational scrutiny of the selected 11 curcuminoids and the standard drug megestrol acetate was useful to identify its likeliness to the protein selected p53. Multiple ligands were taken and docked with the same protein binding site for identifying its interaction. It was observed that the active compounds derived from curcumin like $\alpha$-elemene, (-) $\gamma$-elemene, ar-turmerone, (-) $\delta$-elemene, demethoxycurcumin showed the maximum docking scores amongst the other ligands, when compared to the standard drug, megestrol acetate. Thus the study wraps up that these the naturally occurring molecules acts as significant lead and substitutes for the investigation for novel therapy against endometrial cancer [26].

\section{REFERENCES}

1. U.M. Moll, E. Chalas, M. Auguste, D. Meaney and J. Chumas, Hum. Pathol., 27, 1295 (1996);

https://doi.org/10.1016/S0046-8177(96)90340-8.

2. http://www.who.int/mediacentre/news/releases/2003/pr27/en/.

3. M. Oren and V. Rotter, Cold Spring Harb. Perspect. Biol., 2, a001107 (2010);

https://doi.org/10.1101/cshperspect.a001107.
4. C. Armit, L. Richardson, S. Venkataraman, L. Graham, N. Burton, B. Hill, Y. Yang and R.A. Baldock, Dev. Biol., 423, 1 (2017); https://doi.org/10.1016/j.ydbio.2017.01.023.

5. http://www.rcsb.org/pdb/explore/explore.do?structure Id=5c5a/.

6. http://raptorx.uchicago.edu/StructurePrediction/predict/.

7. V.Vishnu, T.S. Saranya and A.A. Manakadan, Res. J. Pharm. Biol. Chem. Sci., 7, 1098 (2016).

8. http://www.acdlabs.com/resources/freeware/.

9. http://www.molecular-networks.com/

10. http://www.molinspiration.com/jme/index.html.

11. http://1mmd.ecust.edu.cn:8000/predict/.

12. http://www.pharmaexpert.ru/passonline/.

13. http://www.arguslab.com.

14. S.G. Gayatri, V. Vishnu, S. Shibu, T.S. Saranya and A.A. Manakadan, J. Chem. Pharm. Res., 7, 170 (2015).

15. A. Verma, G. Amresh, P.K. Sahu, C.V. Rao and A.P. Singh, Asian Pac. J. Trop. Biomed., 2, 696 (2012); https://doi.org/10.1016/S2221-1691(12)60212-3.

16. J.A. Canner, M. Sobo, S. Ball, B. Hutzen, S. DeAngelis, W. Willis, A.W. Studebaker, K. Ding, S. Wang, D. Yang and J. Lin, Br. J. Cancer, 101, 774 (2009); https://doi.org/10.1038/sj.bjc.6605199.

17. C. Suenderhauf, F. Hammann and J. Huwyler, Molecules, 17, 10429 (2012); https://doi.org/10.3390/molecules 170910429 .

18. N. Thomas and S.M. Zachariah, Asian. J. Pharm. Clin. Res., 6Suppl2, 11 (2013).

19. A.H.S. Kumar, J. Nat. Sci. Biol. Med., 5, 1 (2014); https://doi.org/10.4103/0976-9668.127269.

20. H. Patterson, R. Nibbs, I. McInnes and S. Siebert, Clin. Exp. Immunol., 176, 1 (2014); https://doi.org/10.1111/cei.12248.

21. S.K. Paramashivam, K. Elayaperumal, B.B. Natarajan, M.D. Ramamoorthy, S. Balasubramanian and K.N. Dhiraviam, Bioinformation, 11, 73 (2015); https://doi.org/10.6026/97320630011073.

22. S.A. Khan, S. Kumar and A.M. Maqsood, Int. J. Interdiscip. Multidiscip. Stud., 1, 8 (2013).

23. D. Chandran, L.K. Pappachen, M. Prathap, M.J. Jinsha and G. Jilsha, Int. J. Pharm. Pharm. Sci., 6, 203 (2014).

24. C.M. Nisha, A. Kumar, P. Nair, N. Gupta, C. Silakari, T. Tripathi and A. Kumar, Adv. Bioinform., Article ID 9258578 (2016); https://doi.org/10.1155/2016/9258578.

25. Z. Suba, Recent Patents Anticancer. Drug Discov., 8, 154 (2013); https://doi.org/10.2174/1574892811308020004.

26. M.D. Wessel, P.C. Jurs, J.W. Tolan and S.M. Muskal, J. Chem. Inf. Comput. Sci., 38, 726 (1998). 